\title{
SOBRE EL CUENTO DE LA HONRA DEL MARIDO, DEFENDIDA POR EL AMANTE, ATRIBUÍDO A RODRIGO DE NARVÁEZ
}

De entre las cuestiones planteadas en el estudio del Abencerraje, presenta difícil solución la del cuento de la hoira del marido, defendida por el amante, tal como se encuentra en la versión del Inventario de Antonio de Villegas ". En ella este "(cuento" es un argumento secundario, que abre un paréntesis en la continuidad de la aventura morisca; un "hombre viejon la atribuye al alcaide de Antequera, don Rodrigo de Narváez, contándosela a los enamorados Abindarráez y Jarifa cuando van camino de su voluntaria prisión. Hace más de cuarenta años, en esta revista, J. P. Wickersham Crawford se ocupó del asunto ${ }^{2}$ y señaló los precedentes de este cuento, cuyo argumento resumió D. P. Rotunda en esta fórmula: "Woman falls in love as a result of her husband's praise of her suitor $)^{3}$. Planteado el asunto sólo desde el punto de vista de la génesis del argumento, no puede hallarse al mismo solución definitiva o al menos convincente, $\mathrm{y}$ hay que abrir paso a otro género de consideraciones. Comenté la integración de la anécdota al Abencerraje ${ }^{4}$, y en esta nota añado otros datos a mi interpretación del asunto, y publico un curioso texto en el que la anécdota mencionada vuelve a tomar cuerpo de cxpresión en forma independiente, integrada en una Relación de casos.

1 Véase mi edición del Inventario de Antonio De Vrllegas. Madrid, MCMLV, Colección "Joyas Bibliográficas", tomo I, y MCMLVI, tomo II, págs. 81-83.

2 J. P. WICKERSHAM CRAWFORD : Un episodio de "El Abencerraje" y una "novella" de Ser Giovanni, en RFE, 1923, págs. 281-287.

3 D. P. Rotunda : Motif-Index of the Italian Novella in Prose. Bloomington, 1942, pág. 183, referencia $T$ 13*.

4 El Abencerraje y la hermosa Jarifa, Publicaciones de la Revista de Archivos, Bibliotecas y Museos. Madrid, 1957, págs. 71-78. 
Sobre la relación entre Il Pecorone (la primera novella del mismo) y el Abencerraje, poco puedo añadir. Resulta hacedera, en efocto, la tesis de Crawford cuando pone de relieve que Il Pecorone se difunde impreso a partir de la edición de Milán, 1568, que se sitúa entre 1565, fecha del privilegio usado para la impresión de la obra española, y 1551, fecha del otro privilegio que Villegas "rasgó" por no haber utilizado. Ya dịe que la difusión de $I l$ Pecorone en manuscrito puede retrotraer antes de 1558 el influjo del texto italiano ${ }^{5}$, y que, por tanto, no es argumento decisivo para dar por sentado que el cuento de la honra no estaba en el texto del primer Inventario que no llegó a la imprenta. Sí, en cambio, puede ahora afirmarse que este cuento no se halla en la versión de Toledo, $1561^{6}$. Para ser objetivo, añadiré que se me ocurre otra indicación en favor del posible influjo. Es sabido que el relato del cuento se cierra con un comentario de Jarifa, que parece un tanto sorprendente: "Por Dios, señor, yo no quisiera servidor tan virtuoso, mas él devía estar poco enamorado, pues tan presto se salió afuera, y pudo más con él la honra del marido que la hermosura de la mugerm " Pues bien, estas palabras pueden tener, por el lugar en que se sitúan y, en cierto modo, por la incomprensión de la mujer ante la solución del caso, elación con las que dice Saturnina a Arnetto en la transición entre el fin de esta novela primera y el comienzo de la segunda : "Finita la novella, cominciò Saturnina e disse così : Molto m'è piacuta questa novella corsiderando la fermezza di colui, avendo nelle braccia colei egli aveva cotanto tempo desiderata. Che s'io fossi stata in quel caso, che fu egli, non so ch'io m'avessi fatton ${ }^{8}$.

E1 documento que en esta nota completa esta cuestión nos muestra que la fama de Rodrigo de Narváez (aparte de la vía histórica) perdura no sólo a través de la anécdota del Abencerraje en su relación con los amantes moros, sino también por medio de este cuento de la honra. En

5 La cuestión se había planteado en la crítica del siglo xviri : en una edición de Il Pecorone, Londres, 1793, hay un prólogo escrito con cierto cuidado crítico, y en él se trata de la difusión de la obra en estos términos : «Non molti sono i testi a penna che ci rimangono del nostro Novellieri, benchè d'altronde si sappia che nei passati tempi n'essistessero parecchi, per essere opera che si è sempremai letta con piacere e premura» (tomo I, pág. XXVII). En este mismo prólogo se descubre que una edición de $\mathbf{1 5 5 4}$ de la obra fue en realidad impresa en 1740 en Lucca tomándose el texto de la edición de Venecia, 1560.

- Véase mi artículo El "Abencerraje" de Toledo, 1561. Edición crítica y comentarios, en Anales de la Universidad Hispalense, 1959, XIX, págs. 1-60, en especial página 37.

7 El Abencerraje y la hermosa Jarifa, ed. citada, pág. 337, párrafo 246.

8 En la mencionada edición de Il Pecorone. Londres, 1798, tomo I, pág. 11. 
efecto, en un libro sobre hechos curiosos acontecidos en Córdoba, hallamos la siguiente narración :

... Don Rodrigo de Narváe fue en tiempo de los Reyes Cathólicos Fernando e Ysabel. Fue tan valeroso capitán que los noros lo tenían por espanto de sus fronteras, señalándose más que otro de su tiempo en las cosas de guerra que cada hia se ofrecian. Por estas cosas el rey don

5 Fernando de Aragón le hizo grancies merzedes y le dio la vara de Antequera en confianza haziéndole alcailte de ella, y que pudiese traer ocho alabarderos consigo, y en nuestros tiempos le an confirmado los Reyes esta merzed. Estando, pues, este cavallero ocupado en defensa de la zindad que se le avía dad", sin embargo que los noros fronterizos de Gra-

10 nada los sacavan a escaramuzar cada día, en las quales el buen alcaide se mostrava mui valeroso capitán, stzedió, pues, que en este tiempo estava [en] aquella villa de Antequera una señora casada con un cavallero; puso los ojos el alcaide en ella con mal ánimo; festejávala y servíala en todas maneras que le era posible. Llegó a tanto su pasión que se deter-

15 minó de escalarla la casa estando ausente su marido. La buena señora, luego que sintió la voluntad de el alcaile, se recogió no queriendo dar oídos a sus rrecaudos y peticiones por ser ella mui gran señora y muger de un tan principal cauallero. Cansóse el alcaide viendo que no le aprovechava nada sus diligencias. Fira el alcaide tan llano, apacible y de buen

20 término con todos, que no se tratava otra cosa en la villa sino de su nobleza y bondad, con que tenía ganadas las voluntades de todos, llamándole a boca llena padre de la patria. El marido de la señora que avía pretendido don Rodrigo de Narváez le fue a pedir un negocio harto dificultoso, que pedía para lazerse mucho parentesco y mucha amistad, y de lo uno

25 ni de lo otro avía nada entre los dos, pero fiado en la nobleza del alcaide y sin saver lo que en su casa avía pretendido, le fue a pedir lo que pretendía, y el buen alcaide sin poner impedimento ni benderle la dificultad que avía, le conzedió luego su demanda diziéndole con mucho amor que en otras cosas de más importancia quería le mandase. Viendo, pues, el

30 cavallero la larga mano con que se le abía correspondido y la voluntad con que monstrava para hazerle merzed en lo que se le ofreciese, se partió de él rindiéndole las gracias y haziéndose lenguas donde quiera en alabanza del alcaide. Entre otras ocasiones donde mostró su agradecimiento fue que, viniendo a zenar a su casa, y estando con su muger a la mesa $\mathbf{y}$,

35 viéndole ella tan alegre, le preguntó que de dónde venía y qué era la causa de su contento. El marido le contó lo que le abía suzedido con el alcaide, añadiendo otras mil cosas que en su loor toda la tierra decía, y que él determinava ser pregonero de ellas donde quiera que se hallase. Fue tanto lo que supo dezir que la muger, agradecida de su parte, le escrivió un

40 villete diciéndole que lo mucho que dél avía dicho su marido, avía sido bastante a rendir a la que todo el mundo no vastara, como él lo avía esperimentado, y que, llevada deste agradecimiento, se resolvia en condescender con su voluntad como se lo prometía por aquel villete [que le enviara. Leído el villete] se quedó pasmado, y viendo que se le mandava 45 que fuese aquella noche porque el marido no estaba en casa, disimuló y 
[1e] dixo al ama que lo llevara que le dixesse a su señora que le besaba las manos, y que él aría lo que se le mandava. Sin embargo, pues de salvos conductos que se le abían dado, determinó por lo que suzediese, armarse de todas armas, y encima de ellas se vistió de beiludo verde aludiendo a la esperanza de conseguir su deseo. No quiso el buen cavallero llevar a nadie consigo, y llegado al puesto tiró una china a la ventana de la casa. La señora, que estava en vela, bajó y abrió a su nuevo galán reciviéndole con mil abrazos y todas las muestras de amor que se pueden imaginar. El cavallero quedó en esto más admirado que cuando recivió el villete, y,

55 deseoso de saber la causa, le rogó que se lo dijese, que reciviría mucha merzed y regalo. Ella le respondió que le placía de decír[se]lo, y comenzó de esta suerte: "Avéis de saber, señor alcaide, que cenando los días pasados mi marido y io, benisteis a plática ; y él tomó la mano y ablo y dixo de vos tantas cosas en vuestra alabanza, honrra y nobleza, que no se

60 más pudiera dezir del mejor hombre del mundo. Llamo[o]s, junto con esto, padre de la patria, y que todos, chicos y grandes, hallavan en vos amparo y remedio, y sobre todo, que érades gran servidor de damas y mui cortesano con ellas. Al fin, mi marido quedó muy satisfecho y obligado a la merzed que le hicisteis, y io, de oirle dezir tantas cosas, quedé tan afizionada de vos, que lo que no pudo vuestra importunación, lo ganó en mí vuestra fama, y así me resolví de serviros, y e aguardado esta ocasión, que está fuera mi marido, para satisfazeros de todo lo que fuere vuestra volun. tad, como lo pod[r]éis hazer en la ocasión presente.n El buen alcaide que acavó de [oir] la causa que a la Sra. le auía movido a su libiandad, le-

70 vantándose de la silla le dixo : «No permita Dios ni su Santa Madre que a hombre que tanto bien dixo, haga yo [con él] semejante traición y maldad; y así os suplico que me perdonéis, señora, porque os certifico que no baste todo el mundo a trocarme de este parezer, y a no ser mui agradecido a tan buena y leal voluntad como es la de vuestro esposo.n $\mathrm{Y}$ diciendo esto se volvió a salir por donde entró, quedando la pobre señora abergonzada y confusa de lo hecho, y por otra parte admirada de la leal. tad y bondad del alcaide, pues quiso posponer su gusto y privarse de lo que tanto avía deseado por no ofender a su marido. Fue esto causa para que la señora lo estimase en más de allí en adelante, siendo pregonera de

80 las virtudes del alcaide en las ocasiones que se ofrecían. Todo esto se vino a descubrir después por su confesor, y muerto el alcaide se compusieron romanzes y muchas letras que se an cantado en toda España con grande loa de este famoso cavallero don Rodrigo de Narváez, de quien se a subido hasta las nubes este caso que le suzedió, pero pocos le an imitado la virtud y fidelidad que guardó a su amigo y bienhechoro ${ }^{9}$.

- Libro de cosas notables que han sucedido en la ciudad de Córdoba y a sus hijos en diversos tiempos. Manuscrito 9/5738, Biblioteca de la Real Academia de la Historia, de Madrid, folios 140-142 vuelto; otro ejemplar en el manuscrito 9/5584 de la misma Biblioteca, al que pertenecen los fragmentos añadidos [ ]. En la Biblioteca Colombina, de Sevilla, hay un manuscrito (84-2-6) que contiene otra Relación de casos de esta clase. Tiene una nota preliminar de MANUEL José DÍAZ DE AyoRA y PINEDo en 
En efecto, no es de extrañar que este relato aparezca en un libro de sucesos notables de Córdoba, porque los de esta ciudad siempre sintieron curiosidad por las noticias de Antequera. Gente de linaje ilustre de Córdoba ayudọ a la toma de la que era villa fronteriza, y después los Narváez tuvieron ocasión en estos tratos de extender las ramas de su familia por entre los hidalgos de la ciudad ${ }^{10}$. La relación histórica es, pues, evidente, $y$ en otro aspecto hay que señalar que la trascendencia de la fama de estos Narváez tiende a elegir la vía literaria en esta forma imprecisa de la leyenda; aparece una realidad de tercer orden, que participa, a la vez, de la verdad histórica y de la ficción poética, y que se perpetúa por medio de la tradición que testimonia el párrafo final del texto de la $R e$ lación cordobesa.

Vemos que no se puede establecer con rigor un comentario sobre las influencias considerando sólo las partes del argumento y trozos de textos; más oportuno me parece acercarse al proceso creador que condiciona la aparición de tres de estas versiones de una anécdota general, situadas en una novela italiana una de ellas, y las otras dos referidas a Narváez en distintas circunstancias en los relatos del Abencerraje y en la Relación cordobesa. Los antecedentes del cuento que aquí nos ocupa, de tan lejanos y diversos orígenes, afluyen hasta el Abencerraje del Inventario en una versión adecuada al sentido de la estructura de esta obra. Si la relacionamos con Il Pecorone, entonces, a su vez, hay que tener en cuenta lo que es la novela, a la vez unidad de creación en sí misma y pieza de un libro de novelas que la contiene. E1 (libro de novelas) es, en este caso, la conversación que se tenían frate Arnetto y suora Saturnina. E1 era un joven de honorable familia, gentil y de gran cortesía, que se había hecho fraile, enamorado de la fama de belleza y sabiduría de la monja Saturnina. La primera de las novelas del libro, ésta que consideramos,

que dice que un erudito caballero, don Pedro de Villaceballos y Vera, le ha asegurado que ael compositor del libro fue Pedro Díaz de Rivas, pero que no recuerda dónde leyó esto. Y al margen hay una nota de letra de la mano de B. J. Gallardo que dice : «B. El sesudo y elegante Díaz de Ribas era incapaz de escribir tales paparruchas. B. J. Gallarđo. Año de 1823.» En esta relación de la Colombina, la aventura de Narváez se encuentra en los folios 83v.-85. Véase mi estudio Fuente Ovejuna en el teatro de Lope y de Monroy, Sevilla, 1965, en donde me ocupo de estos Casos notables de la ciudad de Córdoba (págs. 90-91). Los Casos están publicados en Biblibfilos Españoles, XXIV, Madrid, 1949, y requieren un cuidadoso estudio.

10 En efecto, el Nobiliario de Córdoba de ANDRÉS DE MORales trae en los capítulos 351 a 363 del libro VIII una extensa relación de la familia Narváez en que puede hallarse noticia de este arraigo en Córdoba. 
comienza: "Saturnina mia, io ti vuò dire una novella..." ". Ser Giovanni refiere que los fervientes amores de los dos son la materia del libro: "Udendo la leggiadra inventiva, la vaga maniera e gl'innamorati ragionamenti che insieme tenevano, per mitigar la fiamma dello ardente amore, del quale smisuratamente ardevano" ${ }^{12}$. Pero, paradoja que implica la comprensión de los principios culturales en que se apoya el género, la relación amorosa se establece "senza nessuna disonestà. $\mathrm{E}$ così il detto fratre Auretto elebe dalla Saturnina quelle consolazione e quel diletto, che onestamente si possono avere...) ${ }^{13}$. Así dispuesto, pues, el marco, queda amparado el curso de la obra, en la que sólo se busca un entretenimiento adecuado para el carácter de estos amantes que se cuentan el uno al otro las novelas; un lector ajeno a los principios mencionados no puede entonces entender su intención, y un desplazamiento de la anécdota a un ambiente diferente requiere la acomodación a nuevos puntos de consideración. Y esto es lo que ocurre en el Inventario; el marco que representa el Abencerraje es de una naturaleza diferente. Domina el sentido de la frontera, aunque éste sea un relato de murallas adentro, que se supone acontecido en la difícil paz de una Antequera recién ganada. Pensemos que si audaz es la aventura de $I l$ Pecorone, insólita es también la del Abencerraje, sólo que en otro sentido: pocas probabilidades había en una villa de frontera para aventuras de esta índole. En el Abencerraje el cuento de la honra es de un índice inferior a la narración de los hechos vertebrales de Abindarráez y Jarifa, puesto que sólo es una confirmación más de la virtud del héroe cristiano: se trata otra vez de vencer la propia voluntad, y esta vez el vencimiento es sobre la sensualidad. E1 juego se establece con finura combinando la perspectiva de la dama y la de Narváez, que considera la misma cuestión : La dama, espoleada por el ramalazo de pasión ( (... no pudiendo [...] sufrirse en sí...)), se ofrece al alcaide a su voluntad ( $(\ldots$ sin que en mi poder quede cosa que no lo sean...) ${ }^{14}$. Pero cuando Narváez sitúa en su perspectiva el ofrecimiento, entonces percibe, como superior a la "cosa", la honra debida a la condición de la persona. El encaje con el cuadro general del Abencerraje resulta así perfecto, y el cuento de la honra es una variación en tono menor del gran asunto del Abencerraje. De ahí el acondicionamiento del desarrollo: mucho más breve y directo en el Abencerraje (aunque

\footnotetext{
11 Edición citada de Il Pecorone, tomo I, pág. 4.

12 Idem, tomo I, pág. 1.

13 Idem, tomo Ir, pág. 275.

14 Edición citada de El Abencerraje, pág. 336, párrafos 233 y 236.
} 
sin llegar al esquematismo de la anécdota de Ponce de León) ${ }^{15}$, y más pausado en Il Pecorone. Las variaciones de este ritmo no dependen tanto de los elementos comunes de la anécdota como de su diversa valoración. Observemos, por ejemplo, el episodio de la entrevista de la dama y el amante, y el progresivo acercamiento de ambos, que ha de culminar en la brusca separaciọ́n del amante cuando conoce los motivos del rendimiento de la dama. Esste es el contraste:

\section{Abencerraje}

«... le rescibió dulcemente y le metió en su cámara, donde passaron muy dulzes palabras... 16.

\section{Il Pecorone}

«... dove la donna con molta festa lo presse ser mano, e poi l'abbracciò...»

«... E poi la donna fe venire confetti e vini, e bevuto e confettato ch'ebbero insieme, la donna lo presse per mano e disse : Galgano mio, egli è tempo d'andare a dormire, e pero andiance a letto... [...] Entrati che furono in camera, dopo molti belli e piacevoli ragionamenti, la donna si spogliò et entrò nel letto...p

«... E così ragionando sopra questa materia, si spogliò et entrò nel letto allato a colei, cui egli aveva tanto tempo desiderata. E poi che fu entrato sotto le disse... ${ }^{17}$.

La concisión del relato del Abencerraje condensa los otros detalles de Il Pecorone que, considerados aisladamente, pueden tacharse incluso de obscenos, pero que en el conjunto sirven para hacer más relevante el gesto último del amante. El autor español pasa por alto esto, y no se le considere pudibundo, pues en el Abencerraje situó motivos semejantes en el curso de la obra, sólo que no tan concretos como son los del italiano. Pero, por otra parte, extiende el relato por la parte de las reflexiones de la dama por el mal paso que va a dar, que no figuran en Il Pecorone: "... y allí ella echó de ver el yerro que avía hecho [en mandarle llamar] y la vergüença que passava en requerir aquel de quien tanto tiempo avía sido requerida; pensava también en la fama, que descubre todas las cosas; temía la inconstancia de los hombres y la ofensa del marido; $\mathrm{y}$ todos estos inconvenientes, como suelen, aprovecharon a ven-

15 En forma mucho más condensada aparece la anécdota en el Cortesano de Luis Milán : véase mi edición y estudio del Abencerraje citados, págs. 76-77.

16 Edición citada de El Abencerraje, pág. 336, párrafo 235.

17 Edición citada de $I l$ Pecorone, tomo I, pág. 8. 
cerla más, y pasando por todos ellos..." ${ }^{18}$. Es de mayor interés para el autor del Inventario este juego psicológico del caso, en el que la honestidad cuenta como un impedimento, que la condición deleitosa que muestra la dama de Il Pecorone. Esstuviese o no en la primera redacción del Inventario, el hecho es que el cuento de la honra se ha integrado en el Abencerraje no como un postizo, sino desde dentro, atemperándose al conjunto. ¿Fue una acomodación establecida desde el texto de $\mathrm{Il} \mathrm{Peco}$ rone? ¿Se juntó a este hilo el de la anécdota tal como se halla difundida $y$ aplicada a otros personajes? ¿O fue tomada de una versión como la de la Relación por alguna de las vías tradicionales que se mencionan al fin de la obra cordobesa? Io importante, sin embargo, es señalar el carácter de la misma, y la combinación de las piezas en una estructura de ritmo diferente, apropiada al sentido creador de cada versión.

En cuanto a la Relación, es chocante, en primer lugar, encontrar un error histórico tan evidente como situar en tiempo de los Reyes Católicos a este don Rodrigo, si es que se trata del primer alcaide de Antequera, confundiendo a Fernando de Antequera con Fernando el Católico. Parece que, en efecto, éste es Rodrigo de Narváez, el viejo o el bueno, y de nuevo hallamos cómo persigue el anacronismo a esta figura de la frontera, desquiciada también en el Abencerraje. Y Rodrigo vivió en un período en que la historia estaba ya ampliamente documentada, y con poco que se supiese de los hechos de la frontera fácilmente se le podía identificar en las Crónicas de Juan II; y, sin embargo, ahí se queda siempre a caballo entre la leyenda y la realidad, señalando la perduración de esta condición tan propia de nuestra literatura. Ramírez de Arellano ha retrasado la fecha de redacción de este caprichoso relato de la vida cordobesa ${ }^{19}$; su autor sería un buen lector de las obras de moda, y acusa por partida doble las preferencias por el sentimentalismo barroco de los libros cortesanos y la truculencia popular, abocada al pliego de cordel. Es sintomático que de la vida heroica y legendaria de Narváez realce este episodio que en el Abencerraje resulta secundario, y la nueva ordenación de las piezas nos ofrece un sentido diferente en la creación. Es evidente,

\footnotetext{
18 Edición citada de El Abencerraje, pág. 336, párrafo 235.

19 Rafael Ramírez DE AReliano : Ensayo de un Catálogo biografico de escrito. res de la provincia y diócesis de Córdoba, tomo II. Madrid, MCMXXIII, págs. 180-185, número 2808. Indica que esta relación de Casos raros de Córdoba hubo de terminar de escribirse en 1618 ; la fecha conviene con lo que se cuenta sobre los alabarderos, sólo que no son ocho, sino cuatro, los que Felipe III concede a don Rodrigo de Narváez y Rojas, décimo alcaide de Antequera, por cédula de 14 de noviembre de 1608, según cuentan las historias de Antequera.
} 
en primer lugar, que el relato de la Relación es más extenso y circunstanciado que el del Inventario. En el Abencerraje el lector de la obra conoce ya al héroe, mientras que en la Relación hay que presentarlo. Ya dije que había razones históricas para que un cordobés conociese las hazañas del Narváez de Antequera, pero los cauces de la vida discurren de otra manera. Desapareció la frontera y su vigencia creadora procedente de la tensión humana del lugar y su colorido ambiente. Córdoba vive ordenada y quietamente, acompasada por ritmo de campanas; las aventuras galantes y las discusiones sobre la honra están más con el tiempo, y los favores son siempre de agradecer. La Relación está hecha "... por modo de diálogo se refieren entre dos mercaderes, el uno llamado Colodro, y el otro Domingo; escusado que se encontravan en la feria de Daimiel...). La sucesión de anécdotas y sucedidos apenas tiene apoyo en este leve marco externo, que no condiciona el relato con el imperativo de los casos precedentes. Y la terminación nos ofrece el aprovechamiento moral del argumento, ahora dispuesto como lección general (y no como pasatiempo de amantes como en $I l$ Pecorone, o una razón más para afirmar la virtud del alcaide, como en el Abencerraje). La fama del caso traspasó el recato de la confesión, y se extendió de un modo que aún recuerda las características medievales: romances y letras para el canto. I a lección, sin embargo, pocos la siguen, pero al menos queda formulada con el fin de que el arte de la narración, enlazado con la historia y las leyendas de un lugar, sea provechoso para los lectores de la Relación.

De esta manera, pues, con un mismo argumento hemos hallado estos tres desarrollos diferentes, situados en tres contextos distintos y justificado cada uno por la consideración del equilibrio interno de las piezas que lo forman. Y para el caso de Rodrigo de Narváez hemos comentado otro relato más, que apoya la fama literaria del héroe de Antequera, relacionado esta vez con las tradiciones cordobesas.

Francisco López Es'sRada

Universidad de Sevilla. 